\title{
Enhancing national emergency management system for nuclear emergency preparedness and response in the light of the accident at the Fukushima Daiichi nuclear power plant
}

\author{
Reno Alamsyah ${ }^{1, *}$ \\ ${ }^{1}$ Nuclear Energy Regulatory Agency of Indonesia (BAPETEN), Jl. Gajah Mada No. 8, Jakarta 10120, Indonesia.
}

\begin{abstract}
A study has been carried out to enhance Indonesian emergency management system for nuclear emergency preparedness and response. The study is very important considering that Indonesia is a nuclear embarking country. The descriptive-analytic method is used to evaluate the current regulatory infrastructure against relevant international standards and conventions. Then, the results of international peer reviews to the system performed in 2015 and 2016 are also discussed. Finally, lessons learned from the Fukushima Daiichi nuclear accident are analysed as well. The study concluded that Indonesia has its commitment to developing the national emergency preparedness and response system. Furthermore, there are some areas for improvements. Among others, Indonesia needs to harmonized its Laws and fully adapt relevant international standards and conventions. The system should be the priority to be established using an integrated all-hazard approach, which requires leadership and coordination role of the national agency for disaster management. In the light of the Fukushima accident, it was identified that the system should also reflect severe accident scenario, which requires: A wide range of documentation that is to be developed, coordinated and harmonized; a comprehensive justified well-informed decision-making system; competency building scheme; and that all of these have to continually be reviewed and improved.
\end{abstract}

\section{Introduction}

Many important lessons have been learned from the 2011 Fukushima nuclear accident as it was reported comprehensively by the Director General of the International Atomic Energy Agency (IAEA) in 2015. One of the observations and lessons is on the development of a nuclear emergency preparedness and response system [1]. As a nuclear energy embarking country [2], Indonesia is for sure have to further develop the current disaster management system with these lessons learned. In order to do so, the current situation has to be reviewed.

In 2015, Indonesia then invited the IAEA for an Integrated Regulatory Review Service (IRRS) mission. This is a full scope assessment of Indonesian nuclear regulatory infrastructure, including in the area of nuclear emergency preparedness [3]. To be more specific, then Indonesia in 2016 invited the IAEA international team for a peer appraisal of the arrangements in Indonesia regarding the preparedness for responding to a nuclear and radiological emergency (EPREV Mission). This is also a full-scope mission [4].

Besides paying attention to the above peer review, Indonesia as one of the parties of the Convention on Nuclear Safety (CNS) needs to follow-up this convention agenda related to emergency preparedness and response. Meanwhile, the parties of the CNS achieve an agreement namely Vienna Declaration on Nuclear Safety (VDNS) in 2015. If Indonesia would like to develop Nuclear Power Plant (NPP), then it surely has to deliberate the VDNS principles. Nevertheless, with three research reactors currently operated in Indonesia, the country cannot ignore the potency of having a significant nuclear accident, especially from the biggest research reactor with the power of $30 \mathrm{MWt}$, even if NPP does not introduce to the country.

Finally, it is also worth to consider recommendations from the Fukushima comprehensive report provided by the DG of IAEA. Hence, the objective of this paper is to identify some gaps between the current national emergency preparedness and response system to the applicable international standards and conventions, to recognize the results of the international peer reviews, and to review the DG's recommendations in the scope of the emergency management system for nuclear emergency preparedness and response.

\section{Methodology}

There are two laws enacted deals with or related to emergency management, i.e. Law No. 24 Year 2007 on

\footnotetext{
Corresponding author: r.alamsyah@bapeten.go.id
} 
Disaster Management (Law 24/2007) and Law No. 10 Year 1997 on Nuclear Energy (Law 10/1997). The relation of these Laws should be first identified.

In the second phase, to analyse the comprehensiveness of the Laws, they are reviewed with international standards and ratified conventions. In this case, the IAEA standard GSR Part 7, the Convention on Early Notification of a Nuclear Accident and the Convention on Assistance in the Case of a Nuclear Accident or Radiological Emergency, which are commonly called as "the Conventions on Early Notification and Assistance", and the CNS are then used as the references. Furthermore, the principles of VDNS are also underlined.

To complete the study, important points from the results of peer review missions, i.e. the IRRS and EPREV, are also discussed. Challenges, opportunities for improvements and possible action plans are then identified. There might be some points that are the same between gap analysis with international standards and the peer review results since the reviews use the same standards as well. What might be different between the two would be because the reviews also refer to international good practices.

Finally, the DG's recommendations are discussed to identify opportunities for improvement. Due to the fact that Indonesia is an embarking country without any plan during the construction phase of the current situation, therefore this study should be aimed to improve the existing national plan.

The review method used in the whole document is descriptive and analytic in nature. Temporarily, quantitative analysis is limitedly used for item counting.

\section{Results and discussions}

\subsection{Harmonisation of laws}

Law 24/2007 is a basis for the operation of the National Agency Disaster Management (BNPB). Under this Law, nuclear accident falls into a category of technological failure under non-natural disaster type, and 'Nuclear explosion' term is used in its elucidation [5]. In another side, Law 10/1997 [6] defined that nuclear accident is an event causing nuclear damage, and it shall be declared by the Chairman of BAPETEN, and mostly used for the purpose of liability of nuclear damage.

In 2015, Directorate of Technical Support and Nuclear Emergency Preparedness of BAPETEN issued a Guideline on the Organization for National Emergency Preparedness and Response (OTDNN). The scope of this document is to provide guidelines for the operation and working mechanism of the OTDNN to assure that its duties would be carried out in an effective, prompt and efficient manner [7]. Surely this document is very important nationally, and even could be among the top priorities, however, one may wonder the organization proposed this document. This fact demonstrates that both Law should be harmonized in the area of nuclear emergency preparedness and response.

\subsection{International standards and conventions}

The IAEA General Safety Requirements (GSR) Part 7 is an implementing instrument of the IAEA SF-1 Fundamental Safety Principles, where Principle-9 governs emergency preparedness and response [8]. The GSR stated that the goal of emergency preparedness is to ensure that an adequate capability is in place within the operating organization and at local, regional and national levels and, where appropriate, at the international level, for an effective response in a nuclear or radiological emergency [9].

This document also defined that the goals of emergency response are to regain control of the situation and mitigate consequences; save lives; avoid or minimize severe deterministic effects; render first aid, provide critical medical treatment and manage the treatment of radiation injuries; reduce the risk of stochastic effects; keep the public informed and maintain public trust; mitigate, to the extent practicable, nonradiological consequences; protect, to the extent practicable, property and the environment; and to prepare, to the extent practicable, for the resumption of normal social and economic activity [9].

For the above goals, the standard lays down 26 requirements in three main chapters: General, Functional and Infrastructure Requirements. The appendices provide guidance values for restricting exposure of emergency workers and generic criteria for use in emergency preparedness and response.

A study by Apriliani in 2017 [10] compares between GSR Part 7 and BAPETEN Chairman Regulation No. 1 Year 2010 (BCR 1/2010) on the Emergency Preparedness and Response [11]. Out of the above 26 requirements of GSR Part 7, Apriliani's paper found that there is one irrelevant requirement, which is regarding responsibilities of the international organization; 11 requirements need the BCR to be revised, and another 8 requirements shall be added to the regulation [10].

As the GSR Part 7 defines general safety requirements, then the comparison should not only be limited to BCR $1 / 2010$ but also with a broader law, i.e. Law 24/2007 and Law 10/1997. For example, the GSR requires that the emergency management system shall be integrated, to the extent practicable, into an all-hazards emergency management system [9]. Furthermore, the GSR also ask the Government to ensure the coordination of and consistency of national emergency arrangements with the relevant international emergency arrangements [9]. These are beyond the capacity of BCR, which is designed limited to regulate BAPETEN's licensee. Additionally, these requirements are not even available in both Law in concern.

A further examination will find that most of General Requirements (No. 1-5) of GSR Part 7 [9], except on responsibilities of the international organization that is irrelevant, shall be implemented in Law 24/2007. The Functional Requirements (No. 6-19) of the GSR [9] provides a description of function shall be carried out by related competent authorities on disaster management, health, food, agriculture, communication, international relation, and radioactive waste management; and also by 
relevant response organizations. As the main consequence, the Disaster Management Agency (BNPB) shall lead and coordinate the establishment and implementation of the national scheme for nuclear emergency response plan.

The Infrastructure Requirements (No. 20-26) of GSR Part 7 [9] describes national infrastructures that shall be provided and maintained, such as staffing; coordination; plans and procedures; logistic; training, drills and exercises; and quality management program. Under Law No. 10/1997, many regulations of these items are available in facility level. For national level or off-site nuclear facility areas, Law 24/2007 and its implementing regulation shall arrange these infrastructures. Further development of the national scheme for nuclear emergency response plan may refer to the IAEA guidelines, such as GSG-2.1 (2007) on Arrangements for Preparedness for a Nuclear or Radiological Emergency [12] and GSG-2 (2012) on Criteria for Use in Preparedness and Response for Nuclear or Radiological Emergency [13].

The national scheme is also developed with consideration of international conventions ratified by Indonesia. Basically, Article 16 of the CNS stated that the Party shall develop and implement its emergency preparedness system [14]. Moreover, the Conventions on Early Notification and Assistance requires the parties to promptly report to the IAEA and neighbouring country shall any nuclear accident exist [15], and in return the parties may request assistant to the IAEA on emergency preparedness and response; or vice versa offer their assistance to the requesting country facing a nuclear accident [16]. Implementing instrument and method of the conventions should be arranged in national regulations.

Lastly, the first principle VDNS stated that "New nuclear power plants are to be designed, sited, and constructed, consistent with the objective of preventing accidents in the commissioning and operation and, should an accident occur, mitigating possible releases of radionuclides causing long-term off-site contamination and avoiding early radioactive releases or radioactive releases large enough to require long-term protective measures and actions" [17]. Currently, BCR regarding the design of a nuclear power plant (NPP) is under revision adopting the latest version of the IAEA standard SSR-2/1 (Rev.1) on Safety of NPP: Design [18]. International community through the Convention on Nuclear Safety recognized SSR-2/1 (Rev.1) as the means to fulfill the first principle VDNS.

While the second principle of VDNS obliges a comprehensive periodic safety assessment for improvement of the existing facility, the third principle requires requirement and regulation to take into account relevant IAEA standards and, as appropriate, international good practice [17]. The third principle provides a reason for having this gap analysis with the standards.

\subsection{Peer review results}

As a full scope regulatory peer review, the IRRS Mission final report provides 3 Good Practices, 24 Recommendations and 37 Suggestions for Indonesia [3]. In the area of emergency preparedness and response, the IRRS Team found 3 Recommendations and 1 Suggestion, which are mainly regarding coordination mechanism between the relevant organization and improvement of regulation to the current international standards [3].

The final report of EPREV Mission gives $3 \mathrm{Good}$ Practices, 21 Recommendations and 5 Suggestions for Indonesia [4]. The Good Practices identified are: A hospital in Indonesia has implemented an innovative approach to classify and notify the central command centre of a range of safety, security and environmental hazard emergencies; A Local Disaster Management Agency (BPBD) has implemented an innovative communications strategy with helpers that will support a coordinated response during a nuclear or radiological emergency; and, Indonesia is demonstrating commitment to nuclear and radiological emergency preparedness and response by regularly conducting large-scale field exercises [4].

Further analysis by this study found that action plans needed to response for all of the above Recommendation and Suggestion provided are: 8 items associated to establishment or review of national policy; 5 items related with enactment or amendment of regulation; 14 items regarding creation or revision of guidelines or procedures; and, 12 items on implementation phase and delivering the records.

Some of the most of important findings here are concerning: the finalization of national nuclear emergency response plan (NNERP) using an integrated all-hazard approach as a priority; national leadership and coordination role of BNPB in establishing and implementing NNERP; implementation of a unified command and control system for nuclear and radiological emergencies, preferably as part of the system for all types of emergencies; strategy for communicating with the public during a nuclear or radiological emergency, to be further elaborated in practical arrangements; and, requirement should be developed by BAPETEN for the licensees to develop Emergency Action Levels to be used as an essential part of the protection strategy.

\subsection{Fukushima Daiichi accident}

Many observations and lessons have drawn and laid down in the DG of the IAEA Report on the Fukushima Daiichi Accident. This document provides 11 findings on emergency preparedness and response [1], which are mainly regarding to: Preparation for the response to a possible severe nuclear accident; Clear definition of roles, responsibilities, specific duties and competency building for the operating organization and for local and national authorities in an integrated scheme; Arrangements for a comprehensive justified wellinformed decision making on early and urgent protective 
actions for the public, and even if it needed to be extended, modified or terminated, based on understanding of radiological health hazards in a nuclear emergency, addressing public concerns locally, nationally and internationally; and, continual improvement of the system.

It is clear then, that nuclear or embarking country has to develop a comprehensive all-hazards emergency preparedness and response system which should consider a severe accident, the one with high consequences even with a very small possibility. To do so, then: a wide range of document have to be developed, coordinated and harmonized nationally and even internationally; a comprehensive justified well-informed decision making has to be well established, and competency building has to be prepared; and that all of these have to continually be improved.

\section{Conclusions}

Indonesia is demonstrating a commitment to nuclear and radiological emergency preparedness and response by regularly conducting large-scale field exercises. As an embarking country, Indonesia needs harmonized its Laws and to fully adopt international standards and conventions regarding emergency preparedness and response. The NNERP should be the priority to be established using an integrated all-hazard approach. This requires national leadership and coordination role of BNPB, including in the implementation of a unified command and control system for nuclear and radiological emergencies, preferably as part of the system for all types of emergencies; the elaboration of the strategy for communicating with the public during a nuclear or radiological emergency in practical arrangements. Meanwhile, BAPETEN as the regulator should require the licensees to develop Emergency Action Levels to be used as an essential part of the protection strategy.

Lessons learned from the Fukushima Daiichi accident is that Indonesia has to develop NNERP that is considering severe accident scenario and requires: a wide range of document to be developed, coordinated and harmonized nationally and even internationally; a comprehensive justified well-informed decision-making system; and competency building; and that all of these have to continually be improved.

The Author wishes to thanks the management of the Centre of System and Technology Assessment for Nuclear Installation and Material (P2STPIBN) BAPETEN for their full support and facilitating this assessment and presentation of the results in this conference.

\section{References}

1. IAEA, The Fukushima Daiichi Accident: Report by the Director-General (IAEA, Vienna, 2015)

2. Republic of Indonesia, Law No. 17 Year 2007 on the National Long-Term Development Plan of 2005 -
2025 (Indonesian Ministry of National Development Plan, Jakarta, 2007)

3. IAEA, Integrated Regulatory Review Service (IRRS) Mission to Indonesia, Report No. IAEA-NS-IRRS 2015/10 (IAEA, Vienna, 2015).

4. IAEA, Final EPREV Report: Peer Appraisal of the Arrangements in Indonesia Regarding the Preparedness for Responding to a Nuclear and Radiological Emergency (IAEA, Vienna, 2016)

5. The Republic of Indonesia, Law No. 24 Year 2007 on Disaster Management (Indonesian National Board for Disaster Management, Jakarta, 2007)

6. Republic of Indonesia, Law No. 10 Year 1997 on Nuclear Energy (Nuclear Energy Regulatory Agency of Indonesia, Jakarta, 1997)

7. DKKN BAPETEN, Guideline on the Organization for National Emergency Preparedness and Response, 3 (BAPETEN, Jakarta, 2015)

8. IAEA, Fundamental Safety Principles, No. SF-1, 14-15 (IAEA, Vienna, 2006)

9. IAEA, 2015, Preparedness and Response for a Nuclear or Radiological Emergency, No. GSR Part 7 (IAEA, Vienna, 2015)

10. Dewi Apriliani, Proceeding of 2017 Seminar on Nuclear Safety ISSN: 1412-3258, 173-181 (BAPETEN, Jakarta, 2017)

11. The Republic of Indonesia, BCR No. 1 Year 2010 on the Emergency Preparedness and Response (BAPETEN, Jakarta, 2010)

12. IAEA, Arrangements for Preparedness for a Nuclear or Radiological Emergency, No. GSG-2.1 (IAEA, Vienna, 2007)

13. IAEA, Criteria for Use in Preparedness and Response for Nuclear or Radiological Emergency, No. GSG-2 (IAEA, Vienna, 2012)

14. , The Convention on Nuclear Safety, INFCIRC/449, 5-6 (IAEA, Vienna, 1994)

15. , The Convention on Early Notification of a Nuclear Accident, INCIRC/335, 3-4 (IAEA, Vienna, 1986)

16. __ The Convention on Assistance in the Case of a Nuclear Accident or Radiological Emergency, INFCIRC/336, 3-4 (IAEA, Vienna, 1986)

17. IAEA, Safety of NPP: Design, No. SSR-2/1 (Rev.1) (IAEA, Vienna, 1994)

18. _ Vienna Declaration on Nuclear Safety, CNS/DC/2015/2/Rev.1, 3 (IAEA, Vienna, 2015) 